\title{
Comparison of urban form based on different city walls between Quanzhou and Newcastle upon Tyne
}

\author{
Di Wang, Jianyi Zheng \\ Department of Architecture, Huaqiao University, Xiamen, China \\ E-mail: archi_yi@163.com,76112598@qq.com
}

\begin{abstract}
Quanzhou in south-eastern China was built in the Sui Dynasty, having more than 1,000 years of history. Its urban development led to the triple walls in a different period of time. Its unique landscape of multiple walls is a one of the Chinese ancient city patterns. However, the massive stone-built city wall pattern like Newcastle also has more than 1000, years of history in western cities.City walls maintain the preeminence as the city's most powerful fixation line. The expansion of the wall in Quanzhou shows how the time-space changes, while Newcastle's fringe belt is relatively stable, which forms a different urban form. This article mainly compares the following aspects: (1) The development of Quanzhou fringe belt; (2) Differences of fringe belts between the multiple walls city and the sole wall city; (3) Differences of land use in intramural zone between two cities. This paper analyzes the differences of fringe belts caused by city walls between Quanzhou, (China) and Newcastle, (England), and their influence on the urban form between the East and the West.
\end{abstract}

Keywords: Chinese ancient city, multiple walls, fixation line, fringe belt, intramural.

\section{Introduction}

With the rapid changes of urban landscapes in most parts of the world, more attentions have been paid on urban morphology over the past two to three decades (Whitehand,2016). The concept of the urban fringe belt is 'arguably the most important single contribution to urban morphology' (Whitehand, 1987). Over the past few decades, the fringe-belt concept has been formed and widely used in the research of Western urban morphology, and it attracts more researchers to focus on the application of the fringe-belt concept in non-Western world. Some of the urban morpho-logical methods in European countries have been used to the exploration of Chinese cities (Whitehand and $\mathrm{Gu}, 2007 \mathrm{a}$ ), such as the research of the ancient city of Pingyao. Since then, there has been an increasing attention to the cooperation between traditional urban form in China and Europe (Conzen,2012). J.W.R. Whitehand, Michael P. Conzen and Gukai chose Pingyao
China with Com, Italian for comparison. Both of cities possess well-preserved historical urban environments that reflect the urban development traditions of their respective cultures (Conzen,2012). The comparative study is an important breakthrough in the application of Conzenian theory in China and it also make a bridge on the understanding of the dynamics of urban landscapes in different world regions.

This study, which compares fringe-belt development in China and Europe, attempts to provide explanations of the relationship between urban landscapes and city walls. Newcastle upon Tyne with a long history, is a typical city with a single city wall, and the wall has no obvious expansion. Quanzhou is the representative of traditional Chinese cities with multiple city walls. Although the multiwalls are not completely coexisting state, the moats outside the walls have been retained. The main content of this comparative study is the intramural parts of fringe belts, and the key points focus on the different urban landscapes 
under the influence of the single fixation line in Newcastle and multiple fixation lines in Quanzhou.

The continuous histories over one thousand years of the two cities provide a useful context for studying the evolution of the fringe belt from a historico-geographical perspective. Many important questions arise in this context: How did the city wall, as a fixation line, influence on urban landscapes? What are the similarities and differences in the fringe belts formed by multiple fixation lines and single fixation line? Which features of fixation lines have persistent effects on cities today whether in China or the West? According to Conzen's theory, this study analyzes the fringe belt of Quanzhou and Newcastle upon Tyne, and discusses the related questions.

\section{Historical geography of Quanzhou and Newcastle Upon Tyne}

Quanzhou

Quanzhou is located in the southeastern part of China, in plain, closed to Jinjiang River with an outlet to the sea (Fig.1). Despite some previous forms of human occupation developed since the Neolithic Age, the history of Quanzhou as a town began in AD 718 .

With the development of Song Dynasty and Yuan Dynasty, Quanzhou as a port city gradually ushered in a prosperous period. Marco Polo who visited Quanzhou in its heyday proclaimed it to be one of the greatest ports in the world. However, its importance waned as succeeding dynasties discouraged and then prohibited maritime trade in Qing Dynasty. An open "bright city" gradually transformed into a closed siege because of the need to adapt to coastal defense.

Quanzhou's economy is facing recession in the Qing Dynasty. Urban construction is no longer expanding. The existing Quanzhou ancient city zone basically maintains the shape of the Ming and Qing Dynasties. Quanzhou city walls have been modified for many times since ancient times. The impact to the city construction was obvious by using the three walls of the city structure in the Tang, Song,
Ming and Qing Dynasties. Quanzhou is listed as the historical and cultural city of China, although experienced the demolition of the city and the new China after the establishment of the great development, the overall structure of the ancient city is still clear.

\section{Newcastle Upon Tyne}

Newcastle upon Tyne has a long and proud history, documented since Roman times. It is the regional capital and the largest economic hub on the northeastern coast of England(Fig.1).

Behind the protection of these fortifications, Newcastle developed as a merchant and trading community. The most significant commodity in the medieval period was wool, and then the coal trade dominated the market after the 14th century. Newcastle played a major role during the 19th-century Industrial Revolution. Heavy industries in Newcastle declined in the second half of the 20th century. Traditional forms of employment have largely been replaced by more retail and service industries.

Newcastle's traditional urban plan shows the salient features of the European medieval town, and it has been almost completely preserved to the mid-eighteenth century. The city center was largely rebuilt in the 1830's led by the Town Clerk and architects. The town walls had last been used defensively in 1745 and parts were demolished from the 1760's. The changes in its plan caused by the industrial revolution became transformative rather than additive. This left some traditional features as inherited outlines acting as a morphological frame for subsequent alterations but obliterated others(Conzen,1981).

\section{The fringe belts of Quanzhou}

The difference between geography and urban planning in China and Europe is enormous. Most cities in Europe have a lot of information on the history of urban material development, while the planning and mapping of Chinese cities is very limited. The city planning for Newcastle dates back to the $1820 \mathrm{~s}$, and the city's historical geography maps from the mid19th century are particularly detailed, showing 
Table I.

Basic information of city walls

\begin{tabular}{|c|c|c|c|c|c|}
\hline & Founded & & $\begin{array}{l}\text { riod } \\
\text { the Wall) }\end{array}$ & Circumference & $\begin{array}{c}\text { Area } \\
\text { (within the wall) }\end{array}$ \\
\hline $\begin{array}{l}\text { Newcastle } \\
\text { upon Tyne }\end{array}$ & $1080 \mathrm{AD}$ & & century & $3.41 \mathrm{~km}$ & $0.62 \mathrm{~km}^{2}$ \\
\hline \multirow{4}{*}{ Quanzhou } & \multirow{4}{*}{ 700AD } & Inner & $9^{\text {th }}$ century & $3.63 \mathrm{~km}$ & $0.82 \mathrm{~km}^{2}$ \\
\hline & & Middle & $13^{\text {th }}$ century & $8.85 \mathrm{~km}$ & $4.07 \mathrm{~km}^{2}$ \\
\hline & & & & & \\
\hline & & Outer & $14^{\text {th }}$ century & $10.83 \mathrm{~km}$ & $5.55 \mathrm{~km}^{2}$ \\
\hline
\end{tabular}

the development of the entire city's core plots and buildings. In contrast, for Quanzhou, the ancient city planning records are mainly local chorography, which describes the record and intention of the main map without accuracy. Due to urban renewal and planning development, two more detailed maps of the core of Quanzhou city were drawn in 1922(Fig.3) and 1983(Fig.4), which could be used to carry out relevant urban morphological studies and to create important cross-cultural morphological comparisons between the East and the West research basis.

Table I illustrates that the walled area in Newcastle and the area within the inner wall of Quanzhou are similar in size, providing a basis for comparison. However, due to the presence of the middle wall and outer wall of Quanzhou, the effects of them on the inner fringe belt cannot be ignored when doing comparison.

During more than 1200 years, the ancient city walls continued to expand and change. From the beginning of the 1920 s, the outer wall was intermittently demolished, and it had completely disappeared on the ground to the late 1930s. One of the great features of the Chinese city walls is the coexistence of multiple walls, resulting in multiple fixation lines (Fig. 2. a, b, d). Although only the outer wall was left after 1353 (Fig. 2. f), the fringebelt features formed by the early fixation lines were present. Some of them developed into roads, and a large number of moats were retained as water systems. Under the influence of multiple fixation lines, how the fringe belt exert influence on urban landscape is a new issue worthy of discussion and attention.

In this paper, three walls are chosen as the fixation lines, which have a profound impact on the urban landscape. Owing to the existence of triple fixation lines, the formation and development of fringe belt has its own unique characteristics. Multiple fixation lines formed their own fringe belts which closed to each other, unlike three fringe belts (Inner fringe belt, Middle fringe belt and Outer fringe belt) in Como. In the following analysis, the fringe belt formed by the inner wall (AD 718-977) as the fixation line is defined as the first fringe belt; the fringe belt formed by the middle wall (AD 906-1353) is defined as the second fringe belt; the fringe belt formed by the outer wall (AD 1658-1922AD) is defined as the third fringe belt.

First fringe belt. The inner wall was built in Tang Dynasty to strengthen fortifications and protect the ruling class and the core settlements. Like many traditional Chinese cities, the urban layout is based on the standard of the Kaogongji, which has a description of the ideal city. Government agencies are located on the north side of the city, with markets and residential areas on the south side. After thousands of years, the traditional city forms defined by city fortifications and gridded streets are still visible.

As can be seen from the map drew in 1922, there are obvious fringe-belt features in the north and southeast. In the map of 1983, the most obvious change is the construction of Zhongshan North Road to improve the accessibility and makes the real formation of the crossroads. The new road cut the area of the original government agencies in north, and divided the large block into several small plots. With the richness of public life, new facilities 

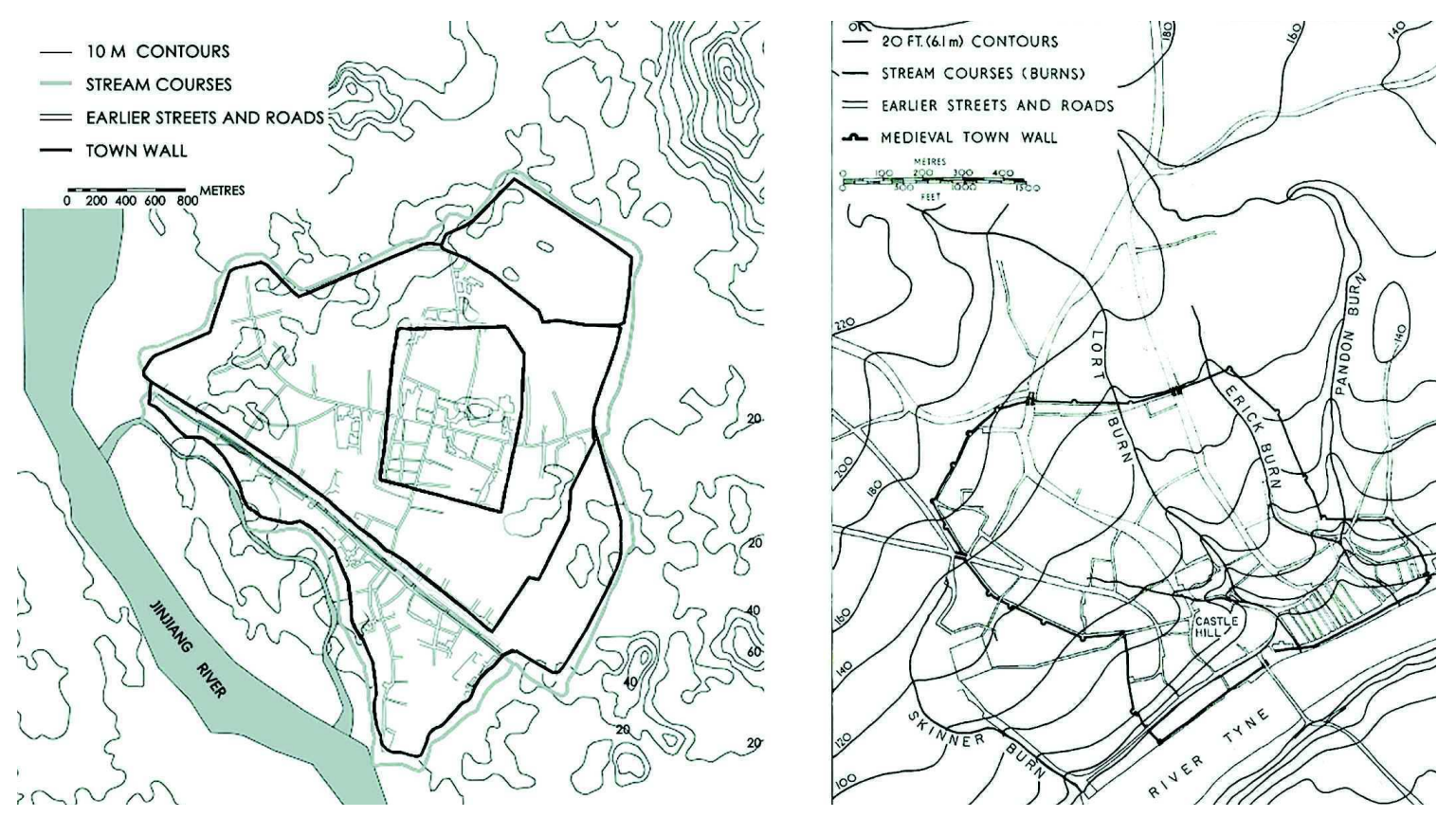

Figure 1.

The site of old town: Quanzhou (left), Newcastle (right) (Conzen,1962)

such as schools, parks and hospitals are become necessities.

Second fringe belt. The middle wall was built in Song Dynasty about five times the size of the inner walled area. Handicrafts and commercial prosperity with the increase in population makes the city to break through the original space and expand the walls. There are three main planning features: Firstly, taking into account the needs of defense, there is a certain space between inner wall and middle wall to avoid direct attack, especially in the north area. Secondly, in the southwest, a commercial street located outside the wall is the main economic activity area in Yuan and Song Dynasty. To meet the needs of maritime traffic foreign trade, the city opened three gates in southwest. Thirdly, the expansion of the city walls is related to military defense and economic development, and is also closely related to religion. In the turbulent era, the ruling group believed in Buddhism and donated a lot of fertile land to temples for peace and blessings. In order to protect the temples, some temples were surrounded by middle wall. The map of 1922 shows that the second fringe belt is mainly composed of low-density villages, cultivated land and temples.

With the continuous development of the city, the middle wall in southwest was removed in 1353 and converted into residential area, but the moat outside the wall retained. The area gradually developed from the extramural of the inner wall to the intramural of the middle wall, and became a deputy center with fringebelt alienation. As the second important commercial street, Tumen street and Xinmen street combined with a traditional axis to become "\#" shape, which constitutes the framework of Quanzhou. The 1983 map shows that the southwest of the second fringe belt facing commercial redevelopment has ceased to be the actual town fringe, while other parts still maintain the features of the fringe belt.

Third fringe belt. The outer wall was built in Ming Dynasty, having a profound effect on modern cityscape. On the basis of middle wall, the direction of urban expanses to the south, north and east of the city. In the 12th century, the national political and economic center moved to the south, attaching great importance to overseas trade. Thus, a stone wall built along the river enclosed the business district, and protected the inhabitants and foreign businessmen. A few hundred years later, due to the relocation, a large number of coastal residents moved into the north of the city, and formed a low-density residential area. In the 

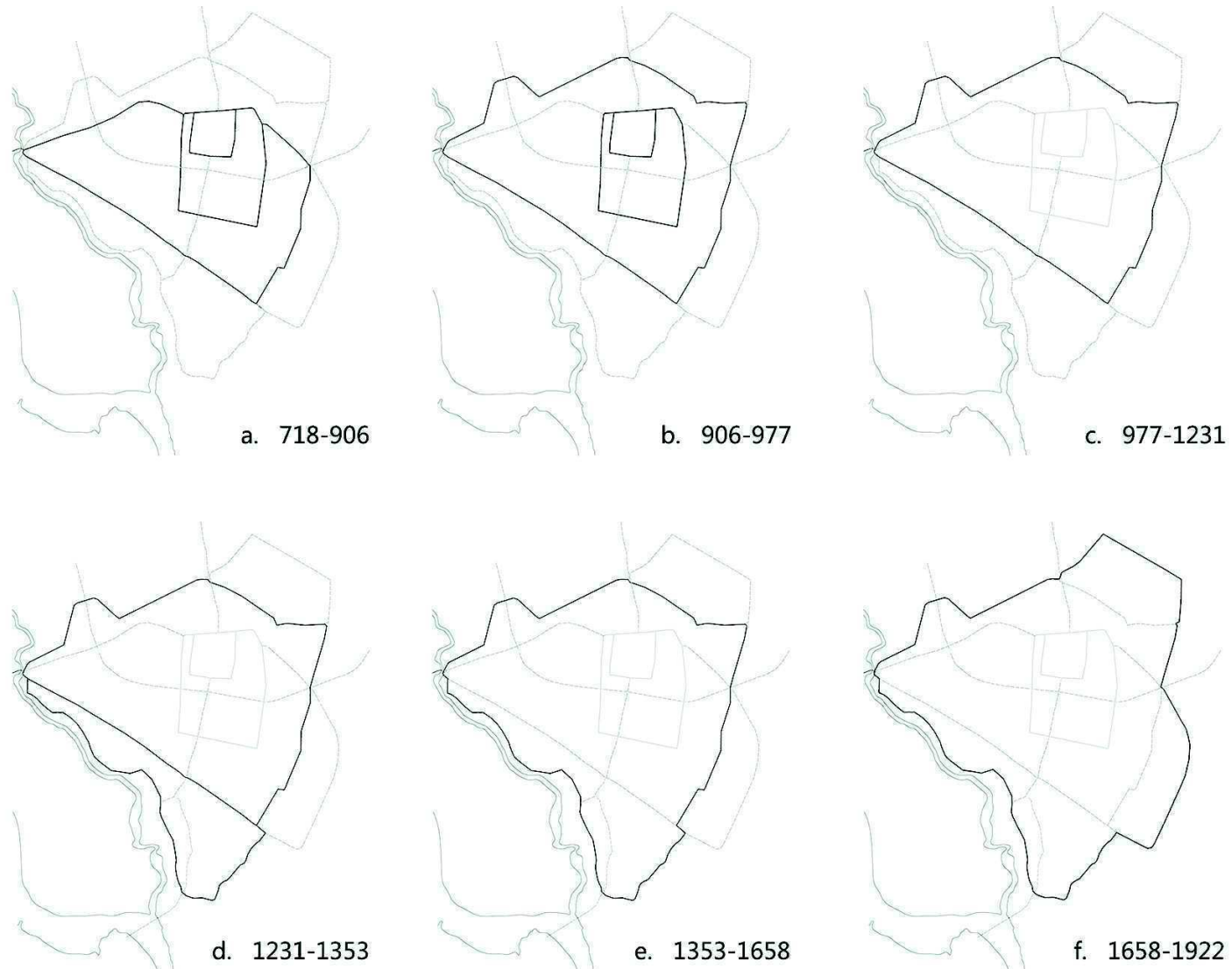

Figure 2.

The process of city wall evolution in Quanzhou

east, an important reason for the expansion is the gradual increase in the surface of the earth due to the movement of the crust. In the 15 th century, the core of the city has been completely changed. The economy declined, while military defense has occupied an important place. Thus, a large area of open space for military practice was added in the south of the third fringe belt. In the 1922 map, it can be seen that in the northwest, the third fringe belt is consistent with the second fringe belt. While the northern and eastern parts of the third fringe belt are in a sparsely populated state, essentially connected to the intramural of the second fringe belt. Only in the southern area, there is a clear feature of the third fringe belt separated from the second one. In the 1983 map, the fringe belt features in north are noticeable while other parts have been very mottled.

\section{Comparison and interpretation}

The differences between single and multiple fixation lines to urban development

The development of fringe belt formed by single fixation line is limited to a relatively narrow area, while the extramural development is more dynamic and coarse-grained, attracting more land use. In Newcastle, due to the development of CBD, the invasion of the wall brings the extramural in closer contact with the CBD. The fringe belt, ultimately, comprises part of the CBD Frame. The effect of fixation lines on the fringe belt is greatly reduced.

The early development of Quanzhou is driven by the expansion of the wall, resulting in that the area inside the wall covers all the functions of the city. Quanzhou's triple fixation 


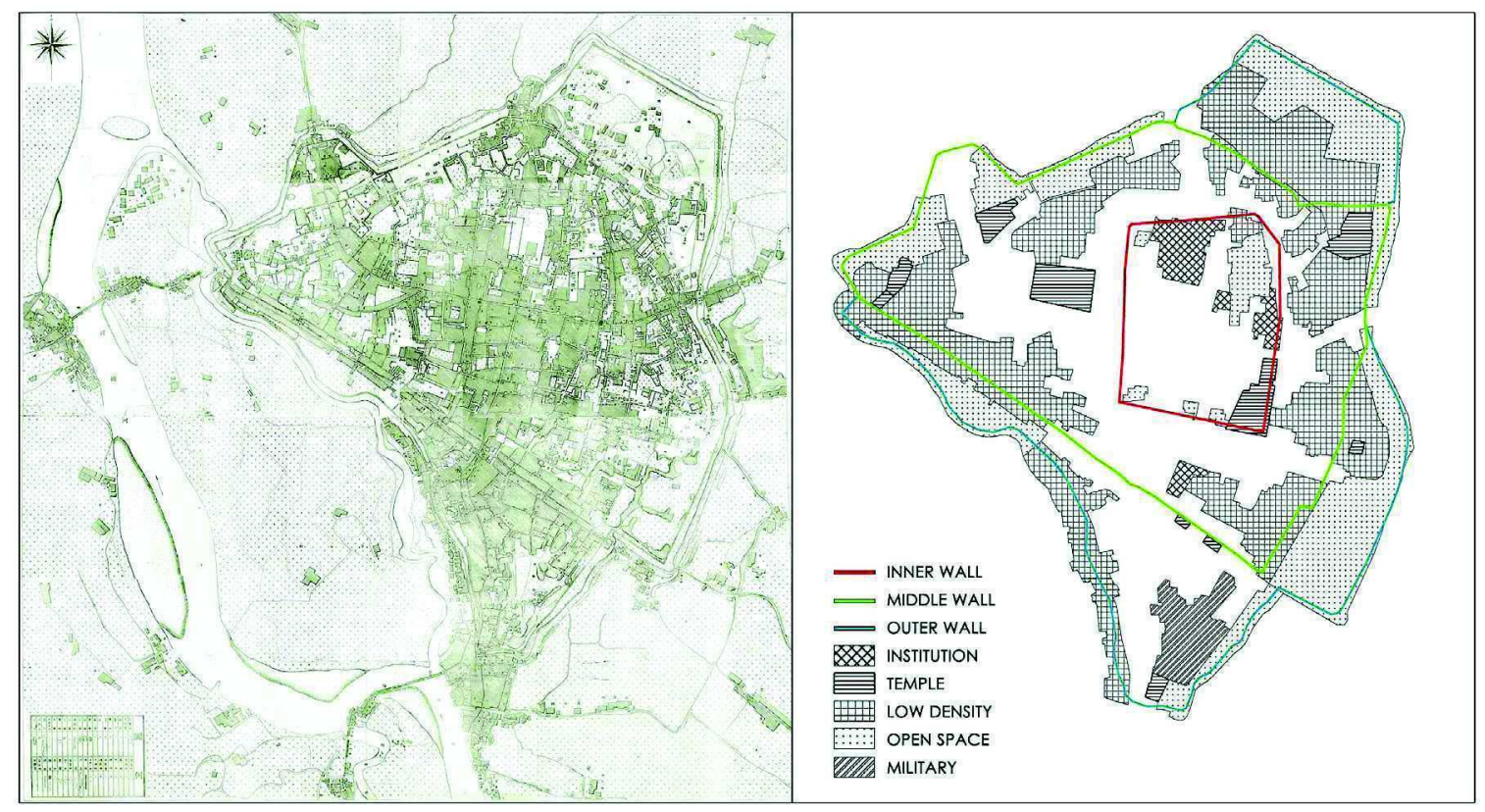

Figure 3.

Quanzhou in 1922.

lines have affected the development of the city. Once the extramural of the inner wall became the intramural of the middle wall, and once the extramural of the middle wall became the intramural of the outer wall. This phenomenon led to the fringe-belt growth inside the outer wall proceeded more piecemeal. Because of the existence of multiple walls, city development of Quanzhou is more compact.

The land use of fringe belt in earlier times

Originally, Quanzhou was built for political purposes, and Newcastle was for military reasons(Fig.5). Quanzhou city wall is almost completed at the same time with the city, reflecting a top-down city planning ideas. In earlier times, the fringe belt of Quanzhou was made up of government agencies, religious sites and open space. Because it is an important political and religious center.

In Newcastle, institutions tended to be among the most space-using land uses. Except in the harbor area $\square$ the intramural had rather large plots containing prominent buildings, such as the 'New House' and 'The Nuns' in the north. Two cities shared some similarities in the land use of fringe belt in the early days.
The changes of fringe belt in modern times

Since the 1950s, the consolidation of the inner fringe belt has shown a greater proportion in Newcastle. All of these represent a new stage in which functional segregation and marginal zone growth are no longer spontaneous, but within the more favorable framework of modern urban planning control. Quanzhou is also the case, listed as "historical and cultural city" in 1986, when the protection of urban landscape increased. The government repaired a group of old buildings and also moved a large number of factories out of the old city. And in the outer wall of the northern, the government planted 12 meters wide green belt to protect and strengthen the existing green area.

It can be seen that the development of early cities is greatly influenced by the fringe belt, while the planning of the city since modern times leads to the changes of fringe belt.

\section{Conclusion}

The multiple fringe belts formed by multiple fixation lines are worthy of study in the definition of fringe belt. The fringe belt 


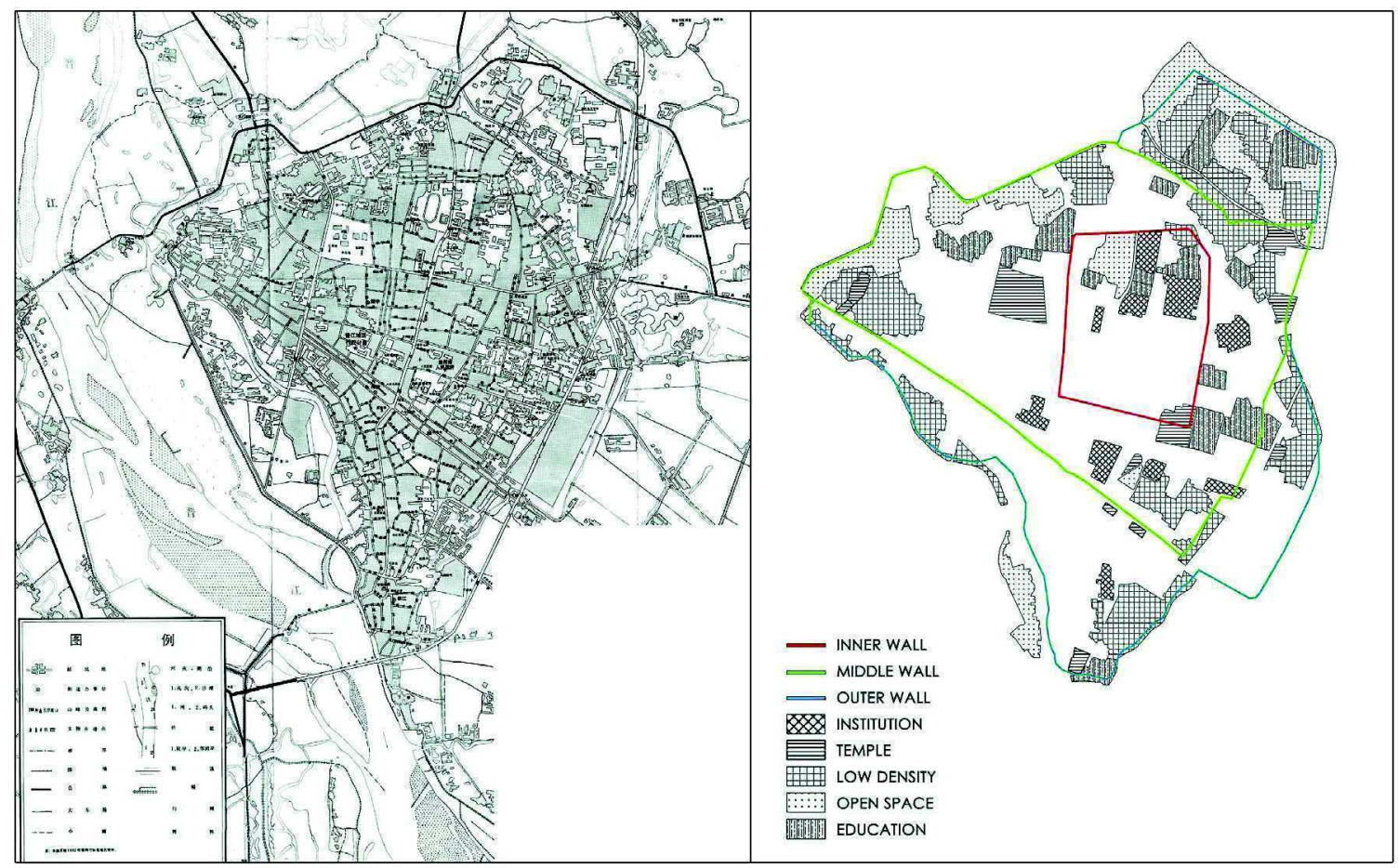

Figure 4.

Quanzhou in 1983.

separates residential growth areas of different historical periods (Whitehand, 2001). The walls fixation lines define the extent of the residential area to some extent, even for a classification of the inhabitants. The fixation lines of ancient China are the product of urban expansion, and the appearance of fixation lines often occurred. It is a new fringe belt model compared with Conzen's theory. Some cities in Europe also have appeared fixation lines, but basically, a new fixation line was constructed after the old one demolished gradually. And it need a long time span to accomplish abovementioned process. The influence between the new fringe belt and the old one is untight.

Comparing with the cultural backgrounds of the two countries, the reasons that led to the huge differences in fringe belts of the two cities were more closely related to the operation of the social policy and the market economy. The development of Newcastle CBD, which leaded to the transformation of the city, made the fringe belt be a part of the framework of developing CBD; City function of Quanzhou has not gravely changed. The fringe belts were full of residential areas, and meanwhile, a large number of public construction had landed.
Studying the planning and development of historical cities can help to analyze the shape and structure of urban landscape. A complete interpretation of the economic, political and social processes of urban development is a great significance to the planning and development of future cities.

\section{Acknowledgement}

This paper is co-funded by the Youth Program of the National Natural Science Foundation (51308232), the National Natural Science Foundation Projects (51578250), the National Science and Technology Support Program of the 12th Five-Year Plan (2015BAL01B01), the Social Development Guidance Project of Fujian Province (2015Y037), the Natural Science Foundation of Fujian Province (2016J01238), Science and Technology Innovation Fund for Young Teachers of Huaqiao University (ZQNPY213).Subsidized Project for Cultivating Postgraduates Innovative Ability in Scientific Research of Huaqiao University 

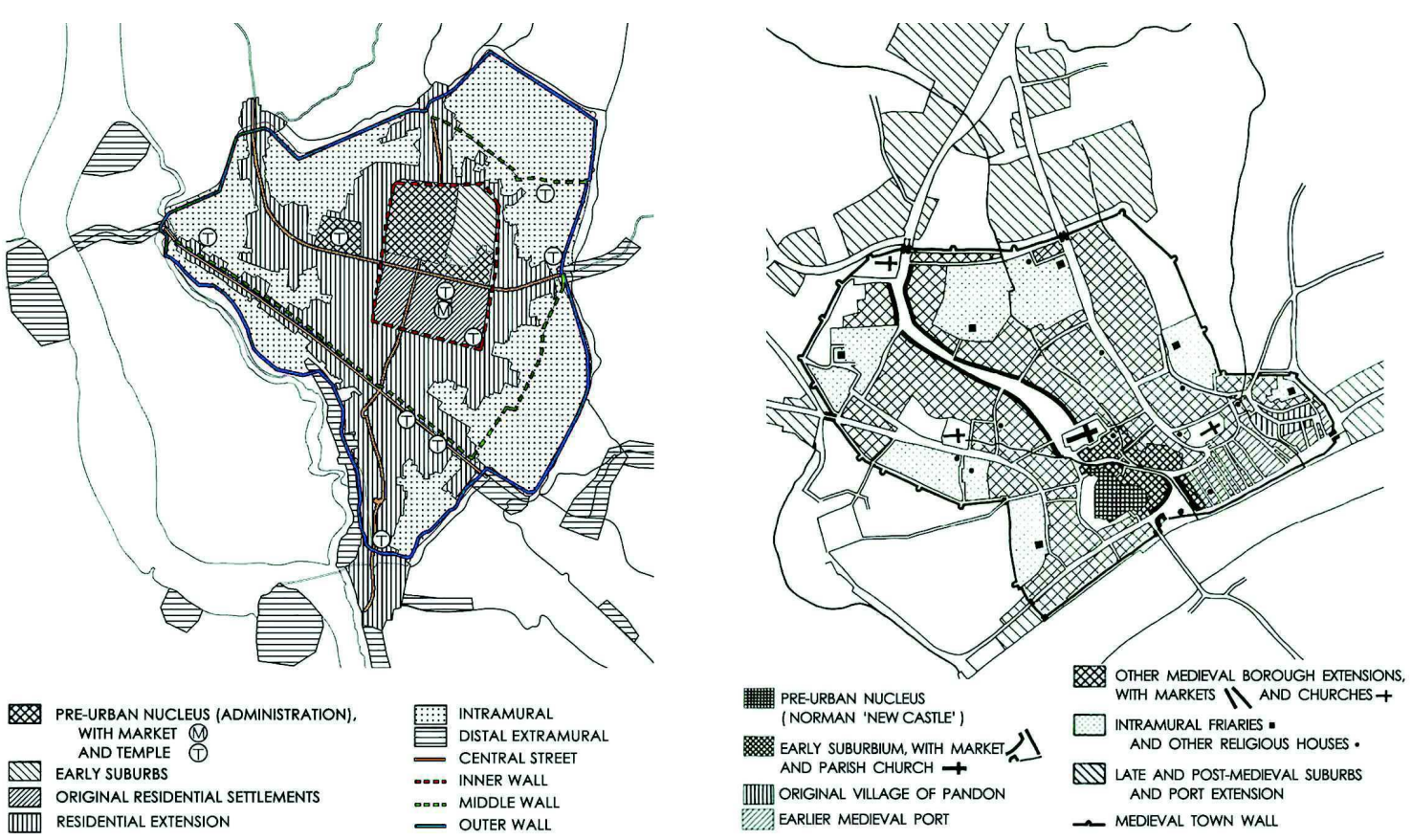

Figure 5.

The plan components of old city: Quanzhou (left), Newcastle (right) (Conzen,1962).

\section{References}

Conzen, M. P., Gu, K. and Whitehand, J. W. R.(2012). Comparing traditional urban form in China and Europe: a fringe-belt approach, Urban Geography, 33, 22-45.

Conzen, M. R. G. (2004) Thinking about urbanform: papers on urban morphology, 1932-1998(Peter Lang, Oxford).

Conzen, M. R. G. (1962). The plan analysis of an English city centre, in Whitehand, J. W. R. (ed.) The urban landscape: historical development and management Institute of British Geographers Special Publication 13 (Academic Press, London) 25-53.

Cullen, F. (2003). Newcastle's grainger town. (English Heritage, London)

Dong, J. (2004). Urban History of China (China Architecture \& Building Press, Beijing)

Faulkner, T. E. (1990) 'The early nineteenth century planning of Newcastle upon Tyne', Planning Perspectives, 5:2, 149-167.

Fung, B (1999). A General Introduction of Macao. Hong Kong: Joint Publishing (H.K.) Co. Ltd.

Gaubatz, P. (2007). The potential for Chinese urban morphology, Urban Morphology, 11, 147-9.
Gu, K., Tian, Y., Whitehand, J. W. R., \& Whitehand, S. M. (2008). Residential building types as an evolutionary process: the Guangzhou area, China. International Seminar on Urban Form.

Pendlebury, J. (1999). The conservation of historic areas in the UK : a case study of "grainger town", newcastle upon tyne. Cities, 16(6), 423-433.

Pendlebury, J. (2001). Alas smith and burns? conservation in newcastle upon tyne city centre 1959-68. Planning Perspectives, 16(2), 115-141.

Tan,Y., (2013). 'Review and exploration of Quanzhou ancient city protection in Fujian', World Architecture, 2001(6):48-52.

Whitehand, J. W. R. (1977). The basis for an historic-geographical theory of urban form, Transactions of the Institute of British Geographers New Series 2,400-16.

Whitehand, J.W.R., and Gu, K.(2007a). Urban conservation in China: Historical development, current practice and morphological approach. Town Planning Review, 78(5), 643-670.

Whitehand, J. W. R., and Gu, K. (2007b). Extending the compass of plan analysis: a Chinese exploration. Urban morphology, 
11(2), 91-109.

Whitehand, J. W. R., Gu, K. and Whitehand,S.M.(2011a) 'Fringe belts and socioeconomic change in China', Environment and Planning B: Planning and Design 38,41-60.

Whitehand, J. W. R., Gu, K., Whitehand, S. M., \& Zhang, J. (2011b). Urban morphology and conservation in China. Cities, 28(2), 171-185.

Zheng, J.Y. \& Liu, G. (2013). 'The evolution and masonry way of the wall area in Quanzhou', Journal of Huaqiao University (Natural Science Edition), 34(2),205-209. 